\title{
THE MOLECULAR BASIS OF VON HIPPEL-LINDAU DISEASE
}

\author{
Othon Iliopoulos and William G. Kaelin, Jr. \\ Department of Medicine, Dana-Farber Cancer Institute and Harvard \\ Medical School, Boston, Massachusetts, U.S.A.
}

\section{THE VON HIPPEL-LINDAU SYNDROME}

von Hippel-Lindau (VHL) disease is an autosomal dominant familial cancer syndrome characterized by the development of retinal angiomata, central nervous system hemangioblastomata, renal cell carcinomas, pheochromocytomata, and endolymphatic sac tumors (1). This disease affects 1 in 36,000 individuals and has a variable but high degree of penetrance (2). The development of renal carcinomas and cerebellar hemangioblastomata are the major causes of morbidity and mortality for VHL patients.

\section{THE VON HIPPEL-LINDAU GENE}

Clinical and molecular epidemiological data have suggested that VHL disease, like hereditary retinoblastoma, is due to inactivation of a tumor suppressor gene (3). In keeping with this view, the VHL gene was mapped to chromosome 3p2526 , a region that is frequently deleted or altered in sporadic renal cell carcinomas. Based on this positional information, a group headed by Drs. Michael Lerman and Bert Zbar cloned the VHL susceptibility gene in 1993 (4). The VHL gene consists of three exons (5), encodes a $4.5-\mathrm{kB}$ mRNA $(6,7)$ and is highly conserved across species $(4,8,9)$. VHL gene mutations have now been identified in $\sim 75 \%$ of VHL families $(10-12)$. Tumor development in VHL patients is associated with somatic loss or inactivation of the remaining wild-type VHL allele, in keeping with the

Address correspondence and reprint requests to: William G. Kaelin, Jr., Dana-Farber Cancer Institute, Department of Medicine, 44 Binney Street, Boston, MA 02115 , U.S.A. Tel.: 617-632-3975; Fax: 617-632-4381; e-mail: william_kaelin@dfci.harvard.edu. notion that the VHL gene functions as a tumor suppressor.

The risk of developing the various tumors that comprise the VHL syndrome differs among VHL kindreds. One classification scheme distinguishes families at low risk (VHL type I) or high risk (VHL type II) of developing pheochromocytomata (13). The latter category is further subdivided into type IIA (low risk of renal cell carcinoma) and type IIB (high risk of renal carcinoma). Certain genotype-phenotype correlations are emerging. For example, missense mutations are often associated with the development of type II disease, whereas mutations predicted to lead to truncated versions of the VHL protein are primarily associated with type I disease $(10,11,13-16)$. It is now also apparent that certain VHL germ-line mutations give rise to familial pheochromocytomata without the other classical manifestations of VHL disease (14,17-19).

A prediction of Knudson's tumor suppressor model is that loss of VHL gene function should also play a role in the sporadic counterparts of the tumors observed in VHL disease. Indeed, inactivation of both VHL alleles, either as a result of mutation, hypermethylation, or loss, has been documented in $\sim 75 \%$ of sporadic renal cell carcinomas of the clear cell type $(12,20-23)$ and $\sim 50 \%$ of sporadic cerebellar hemangioblastomata (24). Mutation of the VHL gene, with loss of the remaining VHL allele (manifest as loss of heterozygosity at the VHL gene locus), has been documented in early premalignant lesions of the kidney, such as atypical cysts and in microscopic renal cell carcinoma in situ $(25,26)$. Thus, inactivation of VHL function appears to be an early, and possibly requisite, step in the pathogenesis of hereditary and sporadic renal carcinomas of the clear cell type. In contrast to renal carcinomas and cerebellar hemangioblastomata, however, 
inactivation of the VHL gene appears to be a relatively rare event in sporadic pheochromocytomata $(20,27)$.

\section{THE VON HIPPEL-LINDAU PROTEIN}

The VHL protein (pVHL) contains 213 amino acid residues and migrates with an apparent molecular weight of $\sim 30 \mathrm{kD}$ (pVHL-L) $(6,8)$. A second VHL isoform ( $\mathrm{pVHL}-\mathrm{S}$ ), with an apparent molecular weight of $\sim 19 \mathrm{kD}$, is generated by translation initiation at an internal ATG (O. I. and W. G. K., unpublished observation). In situ RNA analysis and immunostaining of adult tissues have documented high levels of expression in organs such as the kidney and cerebellum, which are sites of tumor formation in VHL disease (28-30). Immunostaining, as well as biochemical fractionation experiments, suggest that pVHL is largely, but not exclusively, cytoplasmic $(6,29,30)$. Under certain experimental conditions, pVHL appears to "shuttle" between the nucleus and cytoplasm (31). The physiological relevance of this latter observation is currently being investigated.

Reintroduction of wild-type, but not mutant, pVHL into VHL (-/-) renal carcinoma cell lines inhibits their ability to form tumors in nude mice $(6,32)$. With one exception (33), restoration of pVHL function in VHL (-/-) renal carcinoma cells has not led to significant alterations in cell growth in vitro. In particular, pVHL, although capable of suppressing tumor growth in vivo, does not dramatically alter the ability of most renal carcinoma cell lines to grow in low serum or to form colonies in soft agar (6).

\section{The von Hippel-Lindau Protein Binds to Elongin $B$ and $C$}

The predicted pVHL primary sequence does not closely resemble that of any protein whose function is known. In an attempt to understand the mechanisms underlying tumor suppression by pVHL, several groups sought to identify cellular pVHL-binding proteins $(8,34-37)$. Two such proteins, elongin $\mathrm{B}$ and $\mathrm{C}$, bind to a region of pVHL that is frequently mutated in VHL kindreds $(34,35,37,38)$. Elongin $B$ and $C$, when bound to elongin $\mathrm{A}$, generate a transcriptional elongation complex called elongin or SIII (38). pVHL competes with elongin $\mathrm{A}$ for binding to elongin $\mathrm{B}$ and
$\mathrm{C}$, at least in vitro, thereby inhibiting elongin or SIII activity $(35,38)$. Thus, in the simplest view, tumor suppression by pVHL might be due, at least in part, to its ability to modulate the rate of transcription of certain genes as a result of its ability to inhibit elongin/SIII.

\section{The von Hippel-Lindau Protein Inhibits the Accumulation of Hypoxia-Inducible mRNAs under Normoxic Conditions}

VHL-associated neoplasms are typically hypervascular and, on occasion, are associated with paraneoplastic erythrocytosis. The former has been linked to the production of angiogenic peptides such as vascular endothelial growth factor/ permeability factor (VEGF/VPF) and the latter to the production of erythropoietin by the tumor cells. VEGF/VPF and erythropoeitin production are normally induced by hypoxia. Several groups have recently shown that VHL (-/-) cells inappropriately produce hypoxia-inducible mRNAs, such as the VEGF mRNA, under both hypoxic and normoxic conditions $(32,39,40)$. Reintroduction of wild-type, but not mutant, pVHL into these VHL (-/-) cells specifically inhibits the production of these mRNAs under normoxic conditions, thus restoring their previously described hypoxia-inducible profile. It seems likely that the overproduction of hypoxia-inducible mRNAs, including those encoding angiogenic peptides such as VEGF/VPF, contributes to the hypervascular nature of VHL-associated tumors. Conversely, inhibition of VEGF has been shown to inhibit tumorigenesis in vivo and thus might contribute to the ability of pVHL to suppress tumor formation (41). If so, this might help to explain the differential effects of pVHL on tumor cell growth in vitro and in vivo.

Surprisingly, the regulation of hypoxia-inducible mRNAs by pVHL appears to be primarily posttranscriptional rather than transcriptional $(32,39)$. Similarly, the regulation of VEGF mRNA abundance by hypoxia occurs primarily at the posttranscriptional level (42). Hypoxia leads to a marked increase in the stability of the VEGF mRNA. This effect depends upon an AUUUArich region of the VEGF 3' UTR. RNA-gel shift analyses have identified cellular proteins that bind to this region under hypoxic, but not normoxic, conditions (43). In the simplest model, these proteins serve to stabilize the VEGF mRNA. In contrast, these RNA binding proteins can be detected in VHL (-/-) cell extracts under both hypoxic and normoxic conditions and, perhaps 
as a result, the stability of hypoxia-inducible $\mathrm{mR}$ NAs is no longer regulated by changes in oxygen (43).

How might binding to elongin $\mathrm{B}$ and $\mathrm{C}$ contribute to the above-mentioned regulation of hypoxia-inducible mRNAs? One possibility is that elongin/SIII regulates the transcription of a gene encoding a protein involved in the regulation of mRNA stability. A second possibility is that elongin $\mathrm{B}$ and $\mathrm{C}$, when bound to $\mathrm{pVHL}$, directly affect the stability of hypoxia-inducible mRNAs. Such a model might account for the observation that pVHL, elongin $B$, and elongin $C$ are primarily cytoplasmic (39). Finally, regulation of hypoxiainducible mRNA stability by pVHL may be unrelated to its ability to bind to elongin B and C. In this regard, it is clear that some VHL-kindredassociated pVHL mutants retain the ability to bind to elongin $B$ and $C(8,37)$. This latter observation, together with the genotype-phenotype correlations described above, might be explained if multiple biochemical activities contributed to tumor suppression by pVHL, one of which is binding to elongins $\mathrm{B}$ and $\mathrm{C}$.

\section{CONCLUSIONS}

von Hippel-Lindau disease, like many hereditary cancer syndromes, is due to a germ-line mutation affecting a tumor suppressor gene. Inactivation of the VHL gene is also implicated in the pathogenesis of sporadic renal carcinomas and cerebellar hemangioblastomata. A frequently mutated region of the VHL gene product, pVHL, binds to elongin $\mathrm{B}$ and $\mathrm{C}$, two components of a tripartite transcriptional elongation factor called elongin or SIII. pVHL negatively regulates the accumulation of hypoxia-inducible mRNAs, such as that encoding the angiogenic peptide VEGF, under normoxic conditions. Whether elonginbinding and regulation of mRNA stability by pVHL are linked and, more importantly, whether they are necessary or sufficient to account for tumor suppression by $\mathrm{pVHL}$, are questions at the center of current studies.

\section{ACKNOWLEDGMENTS}

We apologize to colleagues whose work was not cited due to space limitations. Othon Iliopoulos receives support from the Murray Foundation and the von Hippel-Lindau Family Alliance.

\section{REFERENCES}

1. McKusick VA (1992) Mendelian Inheritance in Man. The Johns Hopkins University Press, Baltimore.

2. Maher ER, Yates JRW, Harries R, et al. (1990) Clinical features and natural history of von Hippel-Lindau disease. Q. J. Med. 77: 1151-1163.

3. Maher ER, Yates JRW, Ferguson-Smith MA (1990) Statistical analysis of the two-stage mutation model in von Hippel-Lindau disease, and in sporadic cerebellar hemangioblastoma and renal cell carcinoma. J. Med. Genet. 27: 311-314.

4. Latif F, Tory K, Gnarra J, et al. (1993) Identification of the von Hippel-Lindau disease tumor suppressor gene. Science 260: 13171320.

5. Gnarra JR, Duan DR, Weng Y, et al. (1996) Molecular cloning of the von Hippel-Lindau tumor suppressor gene and its role in renal cell carcinoma [review]. Biochim. Biophys. Acta 1242: 201-210.

6. Iliopoulos O, Kibel A, Gray S, et al. (1995) Tumor suppression by the human von Hippel-Lindau gene product. Nat. Med. 1: 822826.

7. Renbaum P, Duh F-M, Latif F, et al. (1996) Isolation and characterization of the fulllength 3 ' untranslated region of the human von Hippel-Lindau tumor suppressor gene. Hum. Genet. 98: 666-671.

8. Duan DR, Humphrey JS, Chen DYT, et al. (1995) Characterization of the VHL tumor suppressor gene product: Localization, complex formation, and the effect of natural inactivating mutations. Proc. Natl. Acad. Sci. U.S.A. 92: 6495-6499.

9. Gao J, Naglich JG, Laidlaw J, et al. (1995) Cloning and characterization of a mouse gene with homology to the human von Hippel-Lindau disease tumor suppressor gene: Implications for the potential organization of the human von Hippel-Lindau disease gene. Cancer Res. 55: 743-747.

10. Chen F, Kishida T, Yao M, et al. (1995) Germ line mutations in the von Hippel-Lindau disease tumor suppressor gene: Correlations with phenotype. Hum. Mutat. 5: 66-75.

11. Crossey PA, Richards FM, Foster $\mathrm{K}$, et al. (1994) Identification of intragenic mutations in the von Hippel-Lindau disease tumor suppressor gene and correlation with disease phenotype. Hum. Mol. Gen. 3: 1303-1308. 
12. Whaley JM, Naglich J, Gelbert L, et al. (1994) Germ-line mutations in the von Hippel-Lindau tumor suppressor gene are similar to somatic von Hippel-Lindau abberations in sporadic renal cell carcinoma. Am. J. Hum. Genet. 55: 1092-1102.

13. Zbar B, Kishida T, Chen F, et al. (1996) Germline mutations in the von HippelLindau (VHL) gene in families from North America, Europe, and Japan. Hum. Mutat. 8: 348-357.

14. Brauch H, Kishida T, Glavac D, et al. (1995) von Hippel-Lindau disease with pheochromocytoma in the Black Forest region in Germany: Evidence for a founder effect. Hum. Genet. 95: 551-556.

15. Neumann HPH, Wiestler OD (1991) Clustering of features of von Hippel-Lindau disease: Evidence of a complex genetic locus. Lancet 337: 1052-1054.

16. Glavac D, Neumann HPH, Wittke C, et al. (1996) Mutations in the VHL tumor suppressor gene and associated lesions in families with von Hippel-Lindau disease from central Europe. Hum. Genet. 98: 271-280.

17. Gross D, Avishai N, Meiner V, et al. (1996) Familial pheochromoccytoma associated with a novel mutation in the von HippelLindau gene. J. Clin. Endocrinol. Metab. 81: 147-149.

18. Ritter $M$, Frilling A, Crossey $P$, et al. (1996) Isolated familial pheochromocytoma as a variant of von Hippel-Lindau disease. J. Clin. Endocrinol. Metab. 81: 1035-1037.

19. Neumann HPH, Berger DP, Sigmund G, et al. (1993) Pheochromocytomas, multiple endocrine neoplasia type 2, and von HippelLindau disease. N. Engl. J. Med. 329: 15311538.

20. Gnarra JR, Tory K, Weng Y, et al. (1994) Mutations of the VHL tumour suppressor gene in renal carcinoma. Nat. Genet. 7: 8590.

21. Shuin T, Kondo K, Torigoe S, et al. (1994) Frequent somatic mutations and loss of heterozygosity of the von Hippel-Lindau tumor suppressor gene in primary human renal cell carcinomas. Cancer Res. 54: 2852-2855.

22. Herman JG, Latif F, Weng Y, et al. (1994) Silencing of the VHL tumor-suppressor gene by DNA methylation in renal carcinoma. Proc. Natl. Acad. Sci. U.S.A. 91: 9700-9704.

23. Foster K, Prowse A, van den Berg A, et al. (1994) Somatic mutations of the von Hippel-
Lindau disease tumor suppressor gene in non-familial clear cell renal carcinoma. Hum. Mol. Genet. 3: 2169-2173.

24. Kanno H, Kondo K, Ito S, et al. (1994) Somatic mutations of the von Hippel-Lindau Tumor suppressor gene in sporadic central nervous systems hemangioblastomas. Cancer Res. 54: 4845-4847.

25. Lubensky IA, Gnarra JR, Bertheau P, et al. (1996) Allelic deletions of the VHL gene detected in multiple microscopic clear cell renal lesions in von Hippel-Lindau disease patients. Am. J. Pathol. 149: 2089-2094.

26. Zhuang Z, Bertheau $P$, Emmert-Buck $M$, et al. (1995) A microscopic dissection technique for archival DNA analysis of specific cell populations in lesions $<1 \mathrm{~mm}$ in size. Am. J. Pathol. 146: 620-625.

27. Hofstra RMW, Stelwagen T, Stulp RP, et al. (1996) Extensive mutation scanning of RET in sporadic medullary thyroid carcinoma and of RET and VHL in sporadic pheochromocytoma reveals involvement of these genes in only a minority of cases. J. Clin. Endocrinol. Metab. 81: 2881-2884.

28. Nagashima $Y$, Miyagi $Y$, Udagawa $K$, et al. (1996) von Hippel-Lindau tumor suppressor gene. Localization of expression by in situ hybridization. J. Pathol. 180: 271-274.

29. Los M, Jansen GH, Kaelin WG, et al. (1996) Expression pattern of the von Hippel-Lindau protein in human tissues. Lab. Invest. 75: 231-238.

30. Corless CL, Kibel A, Iliopoulos O, et al. (1997) Immunostaining of the von HippelLindau gene product (pVHL) in normal and neoplastic human tissues. Hum. Pathol. 28: 459-464.

31. Lee S, Chen DYT, Humphrey JS, et al. (1996) Nuclear/cytoplasmic localization of the von Hippel-Lindau tumor suppressor gene product is determined by cell density. Proc. Natl. Acad. Sci. U.S.A. 93: 1770-1775.

32. Gnarra JR, Zhou S, Merrill MJ, et al. (1996) Post-transcriptional regulation of vascular endothelial growth factor mRNA by the VHL tumor suppressor gene product. Proc. Natl. Acad. Sci. U.S.A. 93: 10589-10594.

33. Chen F, Kishida T, Duh F-M, et al. (1995) Suppression of growth of renal carcinoma cells by the von Hippel-Lindau tumor suppressor gene. Cancer Res. 55: 4804-4807.

34. Kibel A, Iliopoulos O, DeCaprio JD, et al. (1995) Binding of the von Hippel-Lindau 
tumor suppressor protein to elongin B and C. Science 269: 1444-1446.

35. Duan DR, Pause A, Burgress W, et al. (1995) Inhibition of transcription elongation by the VHL tumor suppressor protein. Science 269: 1402-1406.

36. Tsuchiya $H$, Iseda $T$, Hino $O$ (1996) Identification of a novel protein (VBP-1) binding to the von Hippel-Lindau (VHL) tumor suppressor gene product. Cancer Res. 56: 28812885.

37. Kishida T, Stackhouse TM, Chen F, et al. (1995) Cellular proteins that bind the von Hippel-Lindau disease gene product: Mapping of binding domains and the effect of missense mutations. Cancer Res. 55: 45444548.

38. Aso T, Lane WS, Conaway JW, et al. (1995) Elongin (SIII): A multisubunit regulator of elongation by RNA polymerase II. Science 269: 1439-1443.

39. Iliopoulos O, Jiang C, Levy AP, et al. (1996) Negative regulation of hypoxia-inducible genes by the von Hippel-Lindau protein. Proc. Natl. Acad. Sci. U.S.A. 93: 10595-10599.

40. Siemeister G, Weindel K, Mohrs $\mathrm{K}$, et al. (1996) Reversion of deregulated expression of vascular endothelial growth factor in human renal carcinoma cells by von HippelLindau tumor suppressor protein. Cancer Res. 56: 2299-2301.

41. Kolch W, Martiny-Baron G, Kieser A, et al. (1995) Regulation of the expression of the VEGF/VPS and its receptors: Role in tumor angiogenesis. Breast Cancer Res. Treat. 36: 139-155.

42. Levy AP, Levy NS, Iliopoulos O, et al. (1997) Regulation of vascular endothelial growth factor by hypoxia and its modulation by the von Hippel-Lindau tumor suppressor gene. Kidney Int. 51: 575-578.

43. Levy AP, Levy NS, Goldberg MA (1996) Hypoxia-inducible protein binding to vascular endothelial growth factor mRNA and its modulation by the von Hippel-Lindau protein. J. Biol. Chem. 271: 25492-25497. 